\title{
The Cleaning of OAB Universal Covers - An Origin of Smut in Aluminum Alloys
}

\author{
T.H. Shen
}

\section{May 14, 2002}




\section{DISCLAIMER}

This document was prepared as an account of work sponsored by an agency of the United States Government. Neither the United States Government nor the University of California nor any of their employees, makes any warranty, express or implied, or assumes any legal liability or responsibility for the accuracy, completeness, or usefulness of any information, apparatus, product, or process disclosed, or represents that its use would not infringe privately owned rights. Reference herein to any specific commercial product, process, or service by trade name, trademark, manufacturer, or otherwise, does not necessarily constitute or imply its endorsement, recommendation, or favoring by the United States Government or the University of California. The views and opinions of authors expressed herein do not necessarily state or reflect those of the United States Government or the University of California, and shall not be used for advertising or product endorsement purposes.

This work was performed under the auspices of the U. S. Department of Energy by the University of California, Lawrence Livermore National Laboratory under Contract No. W-7405-Eng-48.

This report has been reproduced directly from the best available copy.

Available electronically at http://www.doe.gov/bridge

Available for a processing fee to U.S. Department of Energy and its contractors in paper from

U.S. Department of Energy

Office of Scientific and Technical Information

P.O. Box 62

Oak Ridge, TN 37831-0062

Telephone: (865) 576-8401

Facsimile: (865) 576-5728

E-mail: reports@adonis.osti.gov

Available for the sale to the public from

U.S. Department of Commerce

National Technical Information Service

5285 Port Royal Road

Springfield, VA 22161

Telephone: (800) 553-6847

Facsimile: (703) 605-6900

E-mail: orders@ntis.fedworld.gov

Online ordering: http://www.ntis.gov/ordering.htm

OR

Lawrence Livermore National Laboratory

Technical Information Department's Digital Library

http://www.llnl.gov/tid/Library.html 


\title{
The Cleaning of OAB Universal Covers - AN ORIGIN OF SMUT IN ALUMINUM Alloys
}

\author{
Tien H. Shen \\ Materials Science and Technology Division \\ Chemistry \& Materials Science Directorate
}

\begin{abstract}
The smut that appeared on the universal covers after the $O A B$ cleaning process consists of sub-micron size aluminum particles originating from the machining of these parts prior to cleaning. The rigorous gross and precision cleanings with Brulin in the OAB cleaning process could not completely wash these fine particles away from the surfaces. However, applying a phosphoric acid etch before the cleaning helped to remove these fine aluminum particles. Experimental results again showed that an acid etching before cleaning is essential in preventing the occurrence of smut in aluminum alloy after gross/precision cleaning.

A mechanism, based on the electrostatic $\zeta$-potential, is proposed to explain the occurrence of smut that is often encountered during the cleaning of aluminum alloys.
\end{abstract}

\section{INTRODUCTION}

In July 2001, the universal covers, made of aluminum alloy 6061-T6 (AA6061) developed "smut" after processing through the Optical Assemble Building (OAB). A detailed description of the $\mathrm{OAB}$ gross/precision cleaning process is illustrated in Appendix I. Previous experiences on the cleaning of cast aluminum alloy A356 and wrought AA6061-T6 indicated that the smut was generated by the alloy itself during the acid etching ${ }^{1}$. However, the universal covers did not receive any acid or caustic etch prior to the OAB cleaning process. This implies that the smut must come from a different origin.

To trace the origin of the smut, an experiment was conducted to monitor the smut formation at each step of the $\mathrm{OAB}$ cleaning process. The $\mathrm{OAB}$ cleaning reduced the particles swipe value to level below 83 as shown in Table I, however, the smut was still quite visible from the swipe papers as shown in Figure 1. This suggests that the size of 
the particle in the "smut" was much smaller than the $5 \mu \mathrm{m}$ detecting limit of the Particle Counting Verification System (PCVS). Furthermore, the smut problem seems to be getting worse 24 hours after the precision cleaning as shown in Figure 1 by the darkening of the smudge on the swipe paper. As a remedial precedure, a phosphoric acid etching process developed previously for $\mathrm{NIF}^{2}$ was subsequently applied to these universal covers. After the OAB cleaning, the phosphoric acid etched universal covers showed some improvement in the particle swipes values as shown in Table I. More importantly, the smut was no longer visible on the swipe papers.

Table I Particle swipe results on un-etched versus phosphoric acid etched universal covers.

\begin{tabular}{|c|c|c|c|c|}
\cline { 2 - 5 } \multicolumn{1}{c|}{} & \multicolumn{2}{c|}{$\begin{array}{c}\text { Un-etched } \\
\text { Universal Covers }\end{array}$} & \multicolumn{2}{c|}{$\begin{array}{c}\text { Phosphoric Acid Etched } \\
\text { Universal Covers }\end{array}$} \\
\cline { 2 - 5 } & S/N 291 & S/N 292 & S/N 031 & S/N 290 \\
\hline $\begin{array}{c}\text { Before } \\
\text { Gross Cleaning }\end{array}$ & 193 & 219 & 125 & 90 \\
\hline $\begin{array}{c}\text { After } \\
\text { Gross Cleaning }\end{array}$ & - & 69 & 76 & 54 \\
\hline $\begin{array}{c}\text { After } \\
\text { Precision Cleaning }\end{array}$ & 66 & 78 & 67 & 79 \\
\hline $\begin{array}{c}\text { 24-hour after } \\
\text { Precision Cleaning }\end{array}$ & 69 & 70 & 62 & 62 \\
\hline
\end{tabular}

This investigation was initiated to 1) determine the origin of the smut in the universal covers or aluminum alloys in general, and 2) answer the perennial question of whether it is necessary to etch the NIF parts made from aluminum alloys before the gross/precision cleaning.

\section{ThE NATURE OF THE SMUT}

Figure 2 shows the SEM-BSE image of the particles on the swipe paper collected from an un-etched universal cover (S/N292) after the gross cleaning in the OAB. Most of the particles are much smaller than $5 \mu \mathrm{m}$. The EDXS analyses were conducted on particles collected from the un-etched universal cover (S/N292) after each step of the OAB cleaning process. Appendix II shows the result of the EDXS analyses and the summary of these results is as follows:

\begin{tabular}{c|l} 
Processing Step & Types of Particle found on Swipe Paper \\
\hline Before Gross Cleaning & $\mathrm{Al}$ \\
\hline After Gross Cleaning & $\mathrm{Al}$, iron oxide and stainless steel \\
\hline After Precision Cleaning & $\mathrm{Al}, \alpha$-eutectic, iron oxide and stainless steel \\
\hline 24-hours after Cleaning & $\mathrm{Al}, \alpha$-eutectic, iron oxide and stainless steel
\end{tabular}


The size of the particles in the smut was significantly reduced after each of the cleaning steps, and the majority of the particles were aluminum. After the gross and precision cleanings, some small iron oxide and stainless steel particles from the cleaning tanks were also deposited on the surfaces of un-etched aluminum parts. This suggests that the surfaces of the AA6061 in some way attracted the fine metallic particles during the cleaning process.

\section{THE ORIGIN OF THE SMUT}

The experimental results have shown that the phosphoric acid etch effectively removed the smut from the surfaces of the universal cover. Since no universal cover could be sampled for topographical examination on the smut formation, a set of 6061-T6 samples from a previous experiment ${ }^{2}$ were selected for SEM study. This set of samples contains four different combinations of surface condition and cleaning steps as illustrated below:

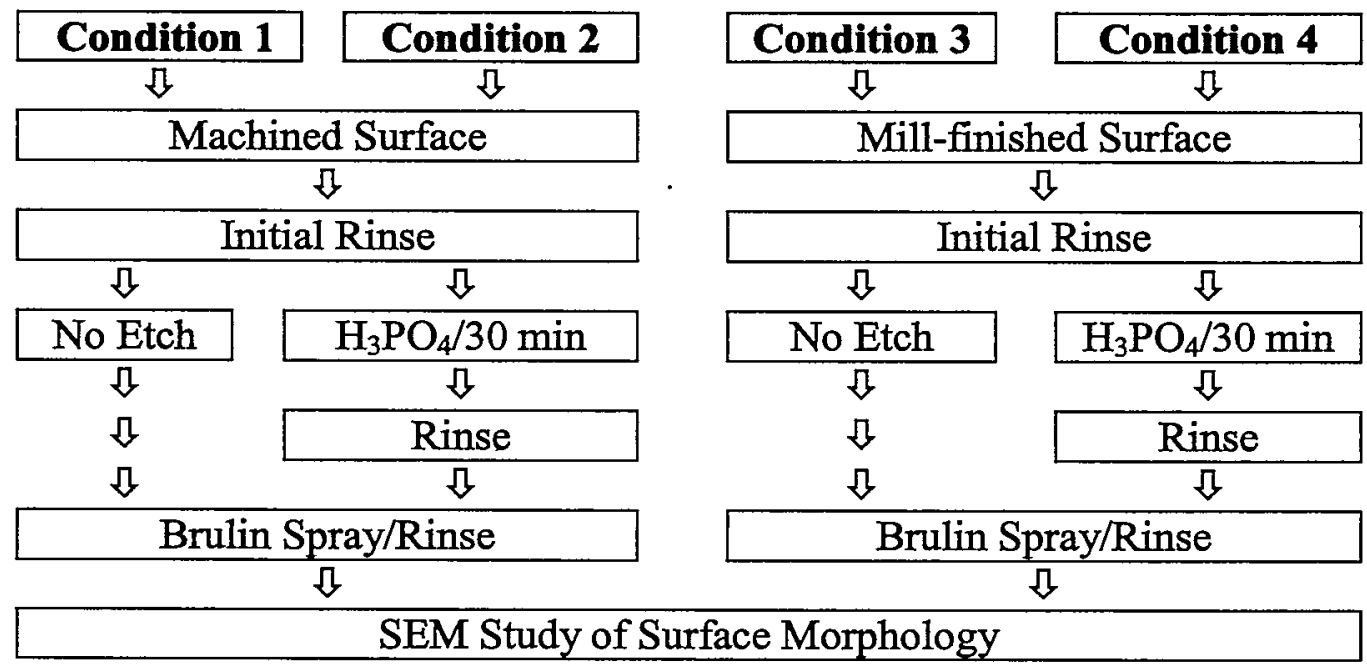

Table II below lists the particles swipe results ${ }^{2}$ as affected by the different initial surface conditions and cleaning/ etching steps.

Table II Results of the particle swipe* on AA6061-T6 with machined and mill-finished surfaces.

\begin{tabular}{|c|c|c|c|c|c|c|c|c|c|c|}
\cline { 2 - 10 } \multicolumn{1}{c|}{} & \multicolumn{4}{|c|}{ Machined Surface } & \multicolumn{4}{c|}{ Mill-finished Surface } \\
\cline { 2 - 10 } & $\begin{array}{c}\text { Initial } \\
\text { Wash }\end{array}$ & $\begin{array}{c}\text { Brulin/ } \\
\text { Rinse }\end{array}$ & $\begin{array}{c}\text { Acid } \\
\text { Clean }\end{array}$ & $\begin{array}{c}\text { Brulin/ } \\
\text { Rinse }\end{array}$ & $\begin{array}{c}\text { After } \\
\text { 14 days }\end{array}$ & $\begin{array}{c}\text { Initial } \\
\text { Wash }\end{array}$ & $\begin{array}{c}\text { Brulin/ } \\
\text { Rinse }\end{array}$ & $\begin{array}{c}\text { Acid } \\
\text { Clean }\end{array}$ & $\begin{array}{c}\text { Brulin/ } \\
\text { Rinse }\end{array}$ & $\begin{array}{c}\text { After } \\
\text { 14 days }\end{array}$ \\
\cline { 2 - 10 } & Step I & Step II & Step II & Step IV & Step V & Step I & Step II & Step III & Step IV & Step V \\
\hline No Etch & 106 & 102 & & & 115 & 341 & 246 & & & 174 \\
\hline Etched & - & - & 144 & 71 & 64 & - & - & 150 & 67 & 69 \\
\hline
\end{tabular}

Figure 3 shows the surface morphology of the sample with machined surface at three magnifications of $100 \mathrm{X}, 500 \mathrm{X}$ and 2,000X. This sample did not receive the phosphoric acid etching. At high magnification, the machined surface was severely torn with fishscale like pattern. Even after the rigorous gross and precision cleanings with high 
pressure spray of Brulin detergent, it is evident that many sub-micron aluminum particles (as indicated by arrows) were still adhered to the rough surface. This resulted in high particle swipe value of level 115 .

Figure 4 shows the surface morphology of a sample with a machined surface that had been etched with $30 \%$ phosphoric acid for 30 minutes prior to cleaning. The machinetorn surfaces were smoothed out slightly by the $\mathrm{H}_{3} \mathrm{PO}_{4}$ etching and the sub-micron aluminum particles were no longer present on the surface. However, the $\mathrm{H}_{3} \mathrm{PO}_{4}$ also attacked the $\mathrm{Mg}_{2} \mathrm{Si}$ precipitates in the matrix and left many pits (as indicated by arrows) behind. The particle swipe values increased right after the acid etch in both types of sample. However, after the precision cleaning, the surface was much cleaner and the swipe values decreased significantly.

As shown in Figures 5 and 6, the samples with mill-finished surfaces exhibited similar results as that of the samples with machined surfaces. In Figure 5 and Table II, the millfinished surface appeared to have many more aluminum particles than that of the machined surface. These fine particles are typical of the aluminum fines generated by the rolling process in the aluminum mill. After the phosphoric acid etch and precision cleaning, the mill-finished surface also reached an acceptable level.

\section{Discussions}

Over the past year, there are several observations often encountered during the cleaning of various aluminum alloys. In general, these observations can be summarized as follows:

1. After several rigorous (high pressure spray) washes with alkaline detergent $\left(\right.$ Brulin $^{B}$ with $\mathrm{pH} \sim 10$ ), most of the particles larger than one micron could be washed away. However, many sub-micron aluminum particles were still firmly attached to the aluminum surfaces as revealed by smudges on the swipe papers.

2. Other types of sub-micron particles that are alien to aluminum alloys, such as iron oxide and stainless steel, were also found on the aluminum surfaces after cleaning.

3. After the gross/precision cleaning, the "smut" sometimes re-appears several days later.

4. During the drying of precision washed parts, high hot air temperature could cause the smut to appear. The $O A B$ has since reduced the hot air temperature from $225^{\circ} \mathrm{F}$ to $150^{\circ} \mathrm{F}$ to prevent this phenomenon from occurring. 
5. Hand-wiping the aluminum surface with polar solvent after the detergent wash helped to remove these sub-micron particles. This is one of the key remedial cleaning steps in bringing down the particle swipe value to below level 83.

6. Etching the aluminum surfaces with phosphoric acid ( $30 \mathrm{vol} \% / 30 \mathrm{~min}$.) before the detergent wash helps to remove the sub-micron particles during the detergent wash.

Apparently, to explain the observations listed above, we require a fundamental understanding about the affinity of sub-micron metallic particles attracting to the aluminum surface. A mechanism, based on the $\zeta$-potential, is proposed as follows:

Electric Double Layer It is well known that the surfaces of all aluminum alloys are actually covered by a thin layer of aluminum oxide $\left(\mathrm{Al}_{2} \mathrm{O}_{3}\right)$. When this oxide film is exposed to water, depending on the temperature and time of the exposure, it will form various forms of hydroxides, such as bayerite, gibbsite and nordstrrandite $\mathrm{Al}(\mathrm{OH})_{3}$, boehmite and diaspore (AlOOH), and $\gamma-\mathrm{Al}_{2} \mathrm{O}_{3}$ and corundum $^{3}$. However, all the hydroxides have a hydroxyl lattice structure in which the bound oxygen atoms will orient the adjacent water molecules to balance the dipole charges over a small distance often called "the electric double layer"4. As the particle size becomes smaller than 1 micron, the influence of the electrostatic potential in this double layer becomes more dominant in affecting the electrochemical behavior of these fine particles.

An electrostatic attractive force ${ }^{5}$, the $\zeta$-potential, can be established between the aluminum surface and the sub-micron particle by the negatively charged hydroxide, oriented water molecules and the abundant supply of cations in the detergent water as illustrated in Figure 7. This electrostatic force is likely the reason that many sub-micron particles are still able to adhere to the aluminum surfaces after the detergent wash. The hydrated aluminum surface not only attracts the aluminum particles, but also all metal oxide particles, such as iron, stainless steel, etc. The existence of a $\zeta$-potential on aluminum surface helps to explain the Observations $1 \& 2$.

After the detergent wash, the aluminum surfaces are exposed to ambient air. However, water molecules are still trapped between the particle and the aluminum surface and maintain the strong electrostatic attraction. Over time, the aluminum hydroxides do dehydrate to various forms of $\mathrm{Al}_{2} \mathrm{O}_{3}$ in air or in inert atmosphere ${ }^{3}$. The dehydration, either through the exposure to ambient air, forced hot air or solvents, takes away the binding agent, water molecules, between the sub-micro particles and the aluminum surface. Thus, the electrostatic attractive force weakens over time and renders the sub-micron particles easy to remove through a physical wiping. The dehydration process helps to explain the Observations 3, 4 \& 5. 
It has been established that the etching of aluminum surfaces with phosphoric acid before detergent wash helps to remove the small sub-micron particles during cleaning.

Although this has become a routine process for cleaning of NIF parts, the reason that it is effective isn't clearly understood. There are three possible mechanisms involved in the acid etching process:

a. Dissolving the aluminum particle Figure 8 shows the SEM micrographs of an aluminum surface before, versus after, the phosphoric acid etching. Before the phosphoric acid etching, there are many sub-micro particles attached to the surface. Most of these particles disappeared after the phosphoric acid etch and the aluminum surface was also etched slightly by the acid. Thus, the phosphoric acid indeed removed the fine particles by dissolving them. Experimental results show that the particles swipe value often increased right after the phosphoric acid etch as shown in Table $\boldsymbol{\Pi}$ and in Reference 2. This suggests that more debris were generated during the etching process. However, these debris could be easily washed away by the subsequent cleaning process. Thus, the phosphoric acid not only dissolved the aluminum particles, but also in some way changed the nature of the aluminum surface.

b. Changing the nature of the surface It is possible that the phosphoric acid can react with $\mathrm{Al}(\mathrm{OH})_{3}$ to form $\mathrm{AlPO}_{4}$ as

$$
\mathrm{Al}(\mathrm{OH})_{3}+\mathrm{H}_{3} \mathrm{PO}_{4} \rightarrow 3 \mathrm{H}_{2} \mathrm{O}+\mathrm{AlPO}_{4},
$$

thus changing the nature of the aluminum surface. A sample etched with $30 \%$. phosphoric acid for 30 minutes had been analyzed by the XPS. Although a small $P$ peak $(\sim 133.8 \mathrm{eV})$ was detected on the surface as shown in Figure 9, a careful analysis of the binding energies of $\mathrm{P}, \mathrm{O}$ and $\mathrm{Al}$ offered no conclusive evidence that $\mathrm{AlPO}_{4}$ was formed. Instead, the XPS data suggests the formation of a metaphosphate, $\mathrm{Al}\left(\mathrm{PO}_{3}\right)_{3}$, on the aluminum surface.

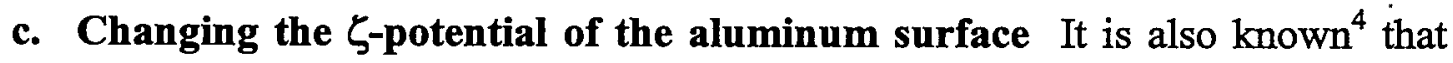
the magnitude of the $\zeta$-potential can be altered by adjusting the $\mathrm{pH}$ in the aqueous solution. As the $\mathrm{pH}$ is lowered by the phosphoric acid, the $\zeta$-potential of the $\mathrm{Al}(\mathrm{OH})_{3}$ is either reversed or approaches zero. This reduces the attraction force and makes it easier to remove the sub-micron aluminum particles. Future experiment will be conducted to measure this effect. 


\section{CONCLUSIONS}

- The smut that appeared on the universal covers after the OAB cleaning process was sub-micron size aluminum particles originated from the machining or mill rolling processes.

- The rigorous gross and precision cleanings with Brulin could not completely dislodge these fine particles from the surface. However, a phosphoric acid etch before the cleaning helped to remove these fine aluminum particles.

- An acid etching before cleaning is essential in preventing the occurrence of smut in aluminum alloy after gross/precision cleaning.

- A mechanism, based on the electrostatic $\zeta$-potential, is proposed to explain the occurrence of smut that is often encountered during the cleaning of aluminum alloys

\section{ACKNOWLEDGEMENTS}

The author would like to express his thanks to Gary Edwards and Christine Choate for providing the results of the OAB cleaning experiment; Ed Lindsey for SEM-EDXS analysis; Cheryl Evans and Art Nelson for XPS analysis and the interpretation of the data.

The valuable discussions with Nerine Cherepy on surface electrochemistry help the author to propose the $\zeta$-potential mechanism. As always, the encouragements and suggestions offered by Bill Gourdin during the course of this investigation and the reviewing of this manuscript are also greatly appreciated.

\section{REFERENCES}

1. Tien H. Shen, Report UCRL-ID-143931, “The Cleaning of Aluminum Frame Assembly Units”, May 2001.

2. Tien H. Shen and Matt Fisher, NIF-0073690 (UCRL-ID-145445), "The Cleaning of Wrought Aluminum Alloy 6061-T6", June 29, 2001.

3. J. W. Diggle and A.K. Vijh, "Oxides and Oxide Films", Vol 4 Chapter 3, in The Anodic Behavior of Metals and Semiconductors Series, Marcel Dekker, Inc., 1976.

4. R.J. Hunter, "Zeta Potential in Colloid Science - Principle and Application", Academic Press, 1981.

5. Private communication with Nerine Cherepy. 


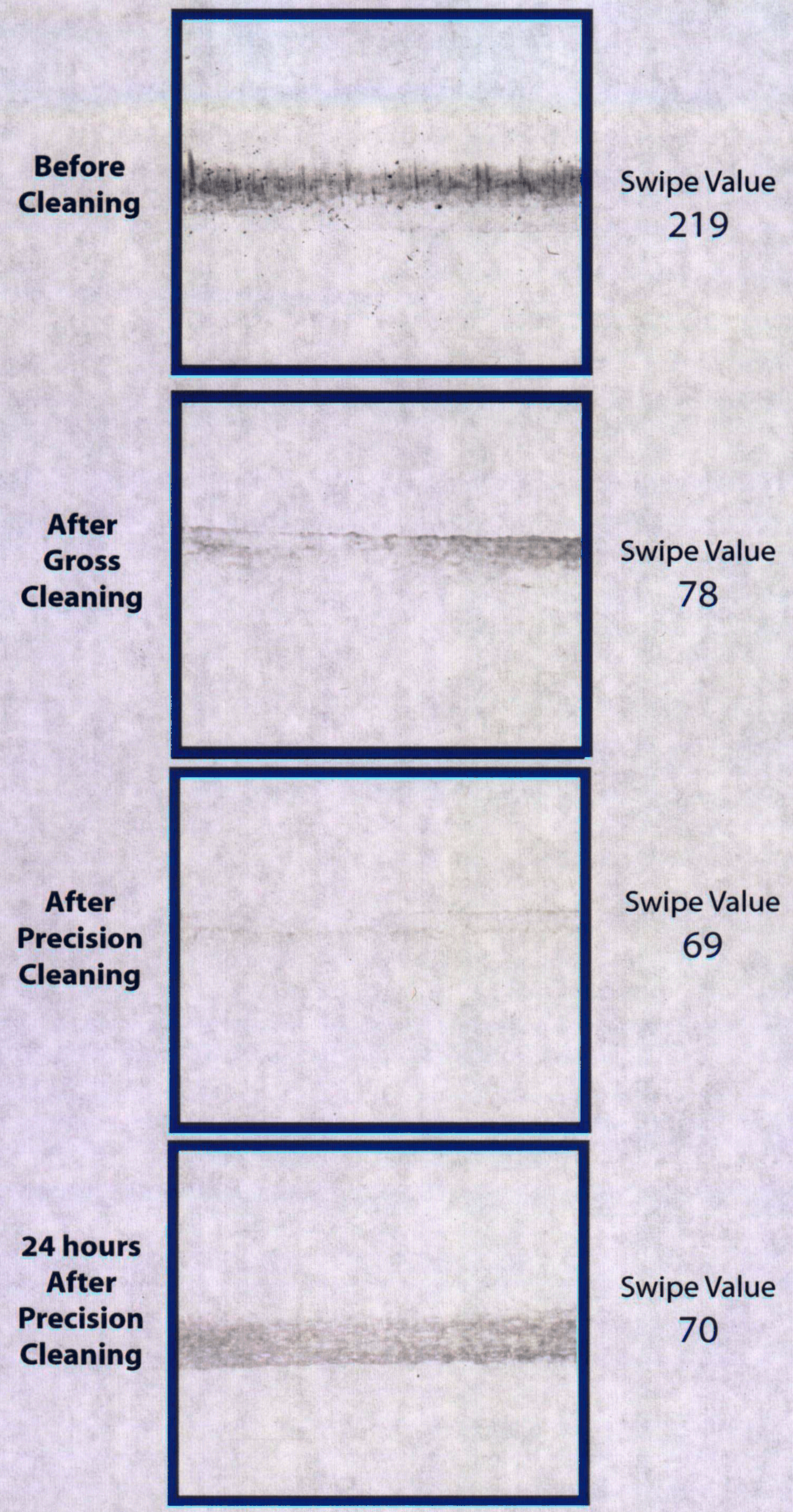

Figure 1 After the $\mathrm{OAB}$ cleaning, the particle swipe reached an acceptable level of below level 83. However, the smuts were still visible from the swipe paper. The smut problem appeared to be worsen 24 hours after the precision cleaning. 


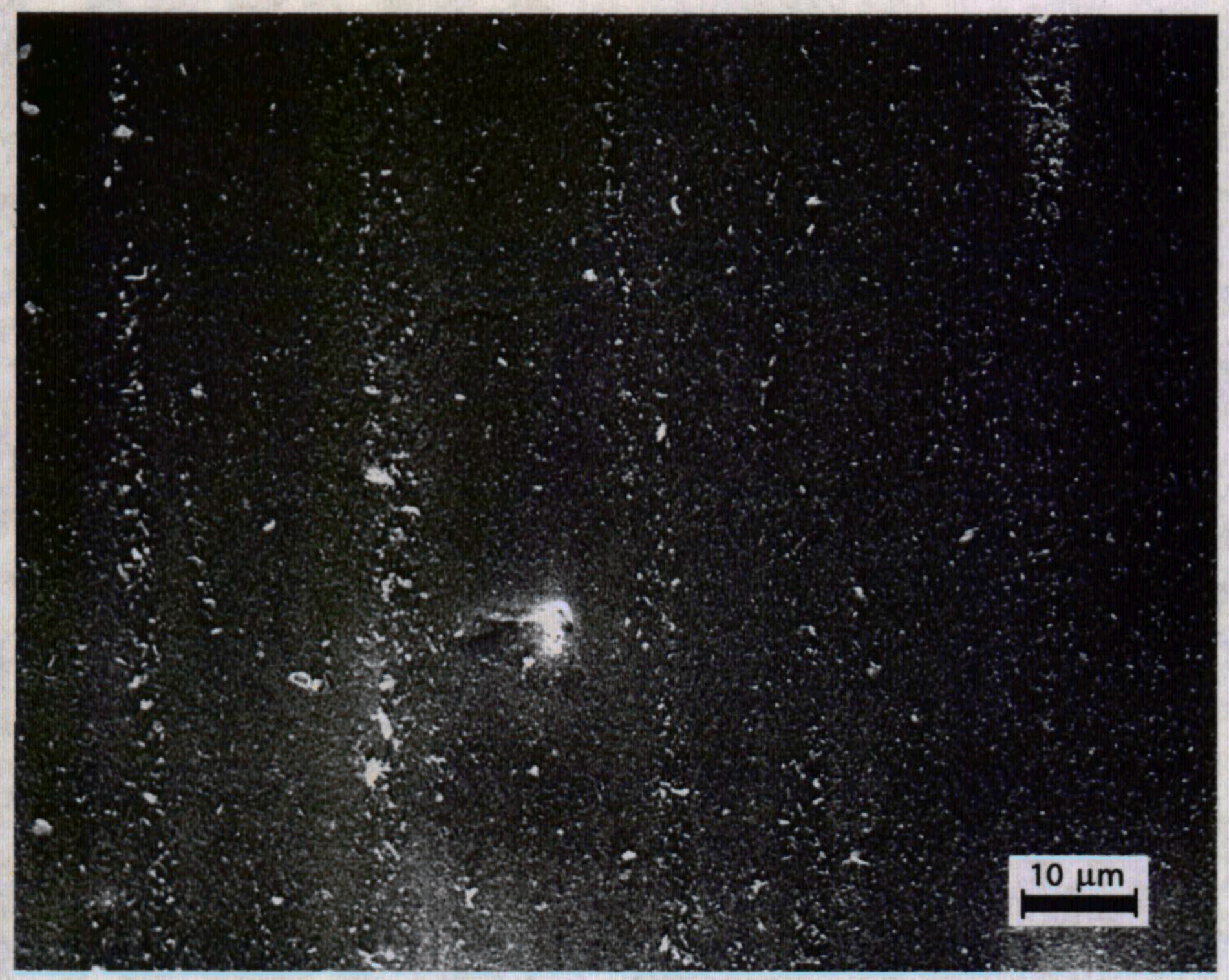

Figure 2 The SEM-BSE image of the particles on the swipe filter paper collected from the universal cover after the gross cleaning in OAB. This universal cover did not receive the phosphoric acid etch before cleaning. 

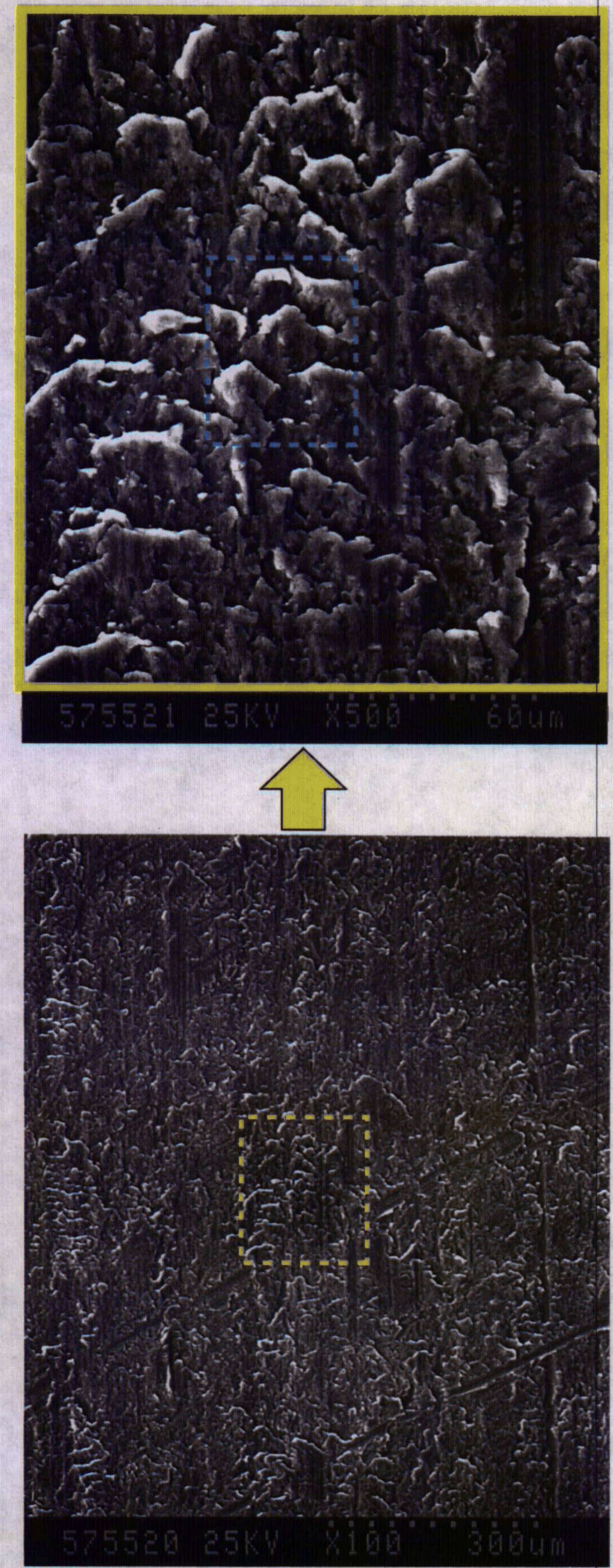

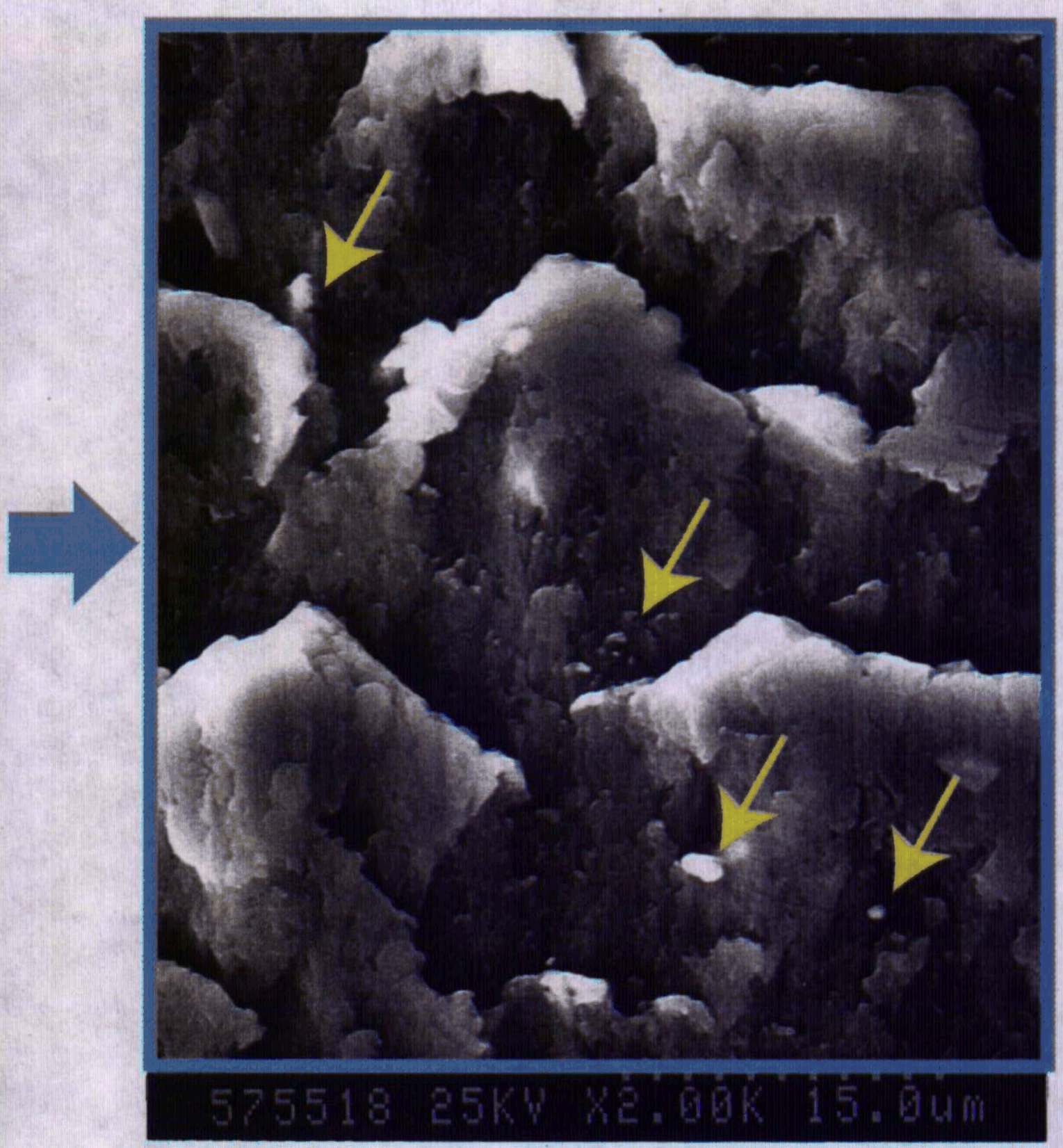

Figure 3 Surface morphology of a AA6061-T6 plate with as-machined surface at three magnifications of $100 \mathrm{X}, 500 \mathrm{X}$ and 2,000X. This plate did not receive the phosphoric acid etching. Many sub-micron aluminum particles (as indicated by the arrows) were still attached to the severely torn surface after the gross and precision cleanings. 

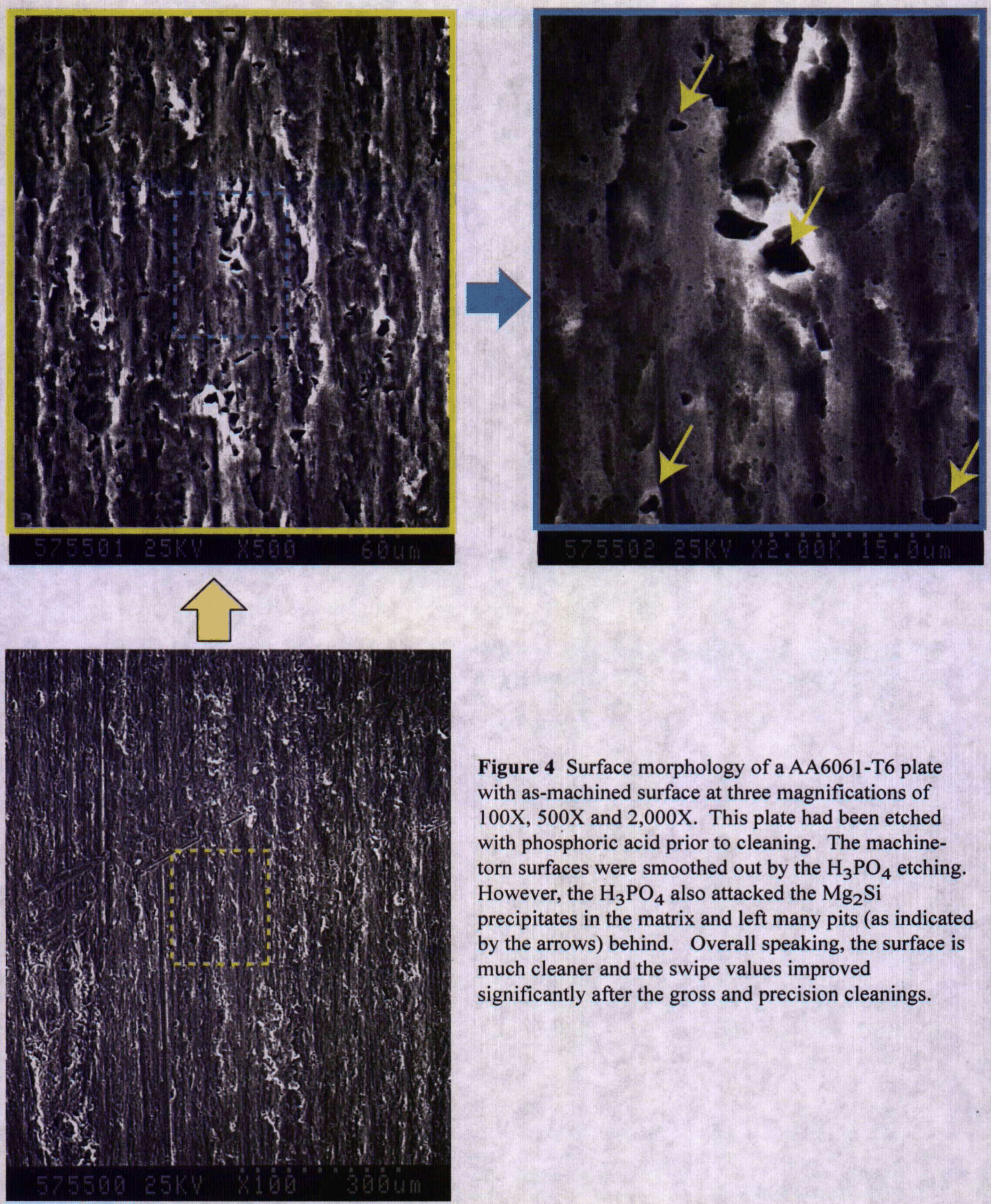

Figure 4 Surface morphology of a AA6061-T6 plate with as-machined surface at three magnifications of $100 \mathrm{X}, 500 \mathrm{X}$ and 2,000X. This plate had been etched with phosphoric acid prior to cleaning. The machinetorn surfaces were smoothed out by the $\mathrm{H}_{3} \mathrm{PO}_{4}$ etching. However, the $\mathrm{H}_{3} \mathrm{PO}_{4}$ also attacked the $\mathrm{Mg}_{2} \mathrm{Si}$ precipitates in the matrix and left many pits (as indicated by the arrows) behind. Overall speaking, the surface is much cleaner and the swipe values improved significantly after the gross and precision cleanings. 

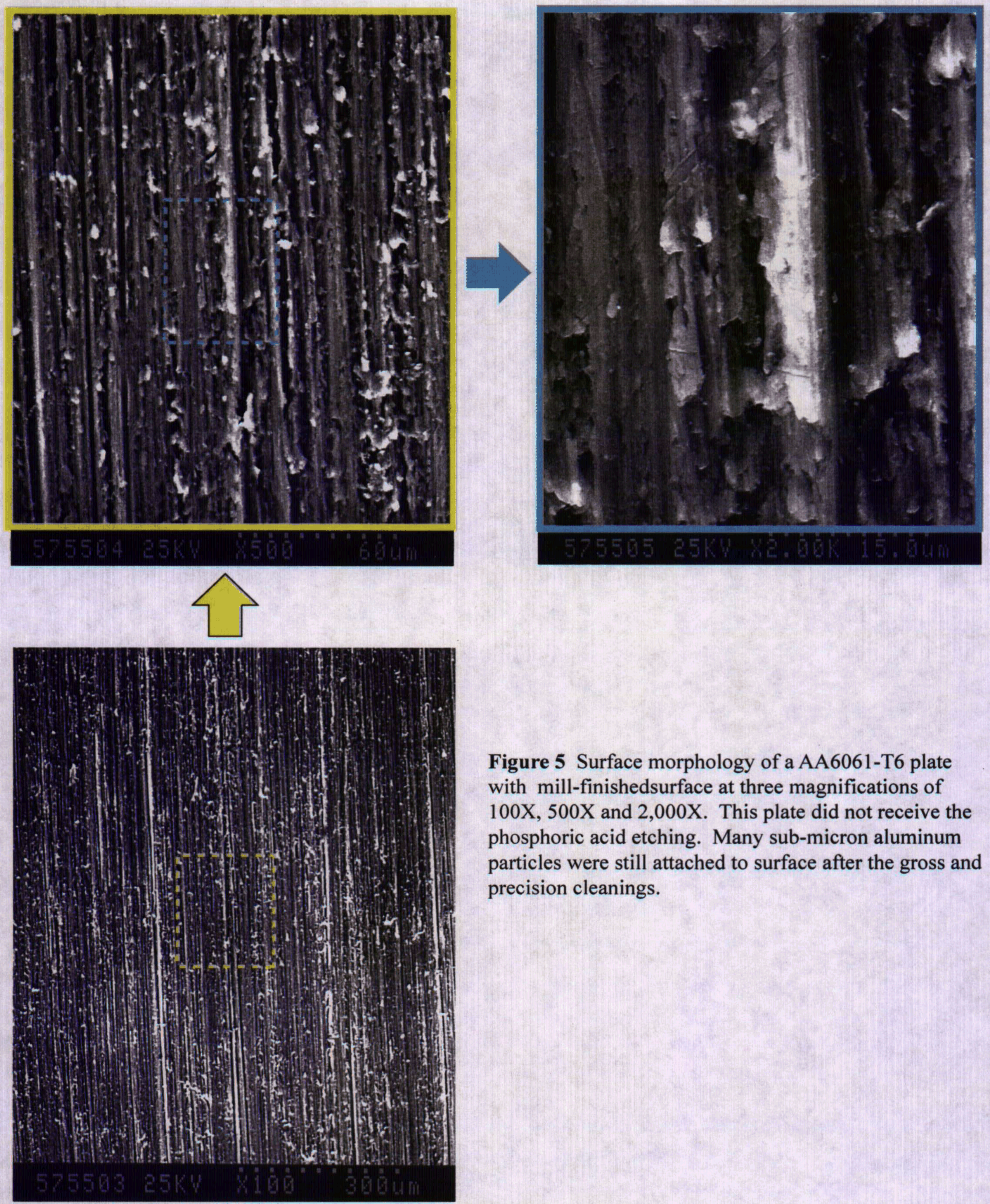

Figure 5 Surface morphology of a AA6061-T6 plate with mill-finishedsurface at three magnifications of $100 \mathrm{X}, 500 \mathrm{X}$ and 2,000X. This plate did not receive the phosphoric acid etching. Many sub-micron aluminum particles were still attached to surface after the gross and precision cleanings. 

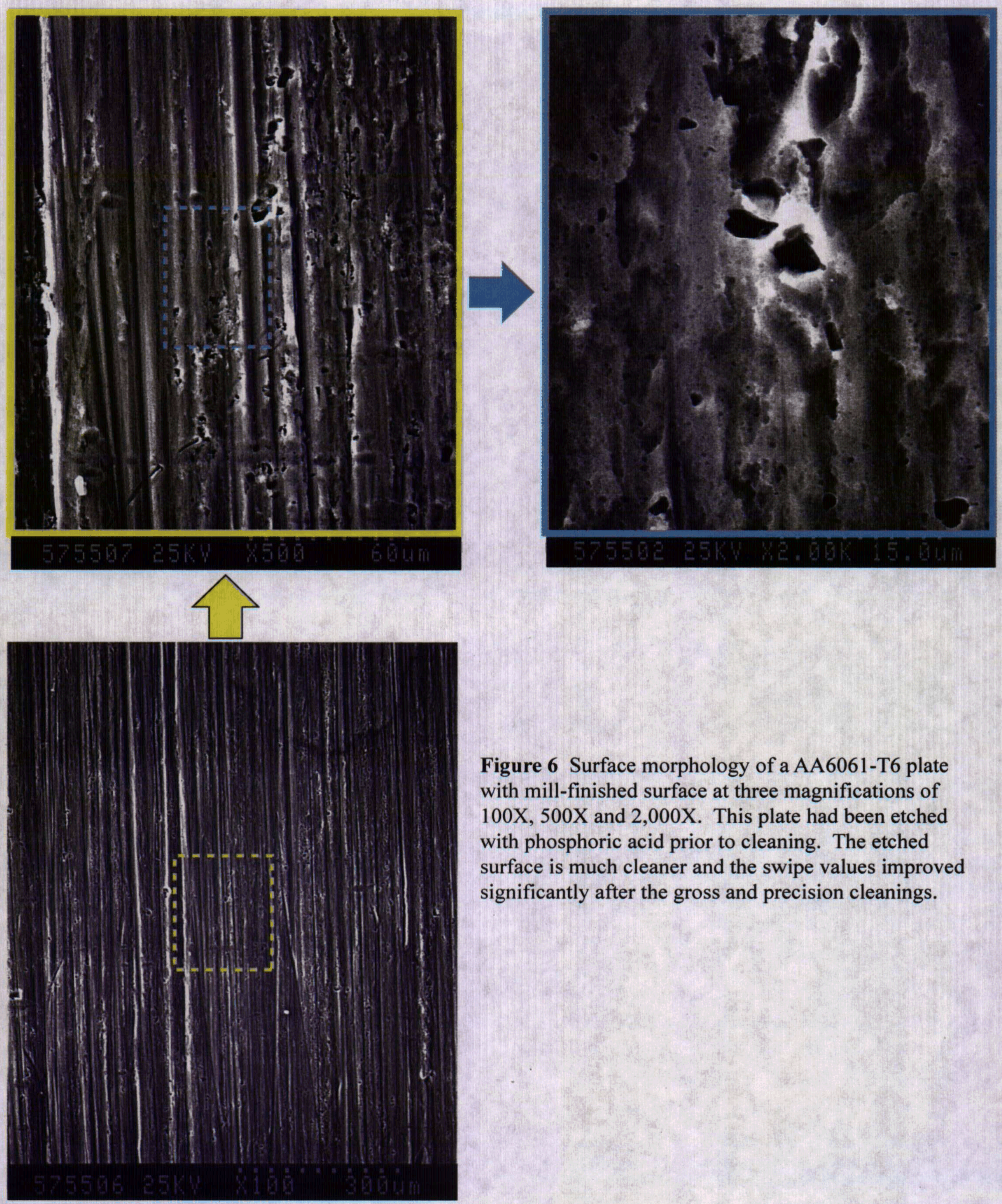

Figure 6 Surface morphology of a AA6061-T6 plate with mill-finished surface at three magnifications of $100 \mathrm{X}, 500 \mathrm{X}$ and 2,000X. This plate had been etched with phosphoric acid prior to cleaning. The etched surface is much cleaner and the swipe values improved significantly after the gross and precision cleanings. 


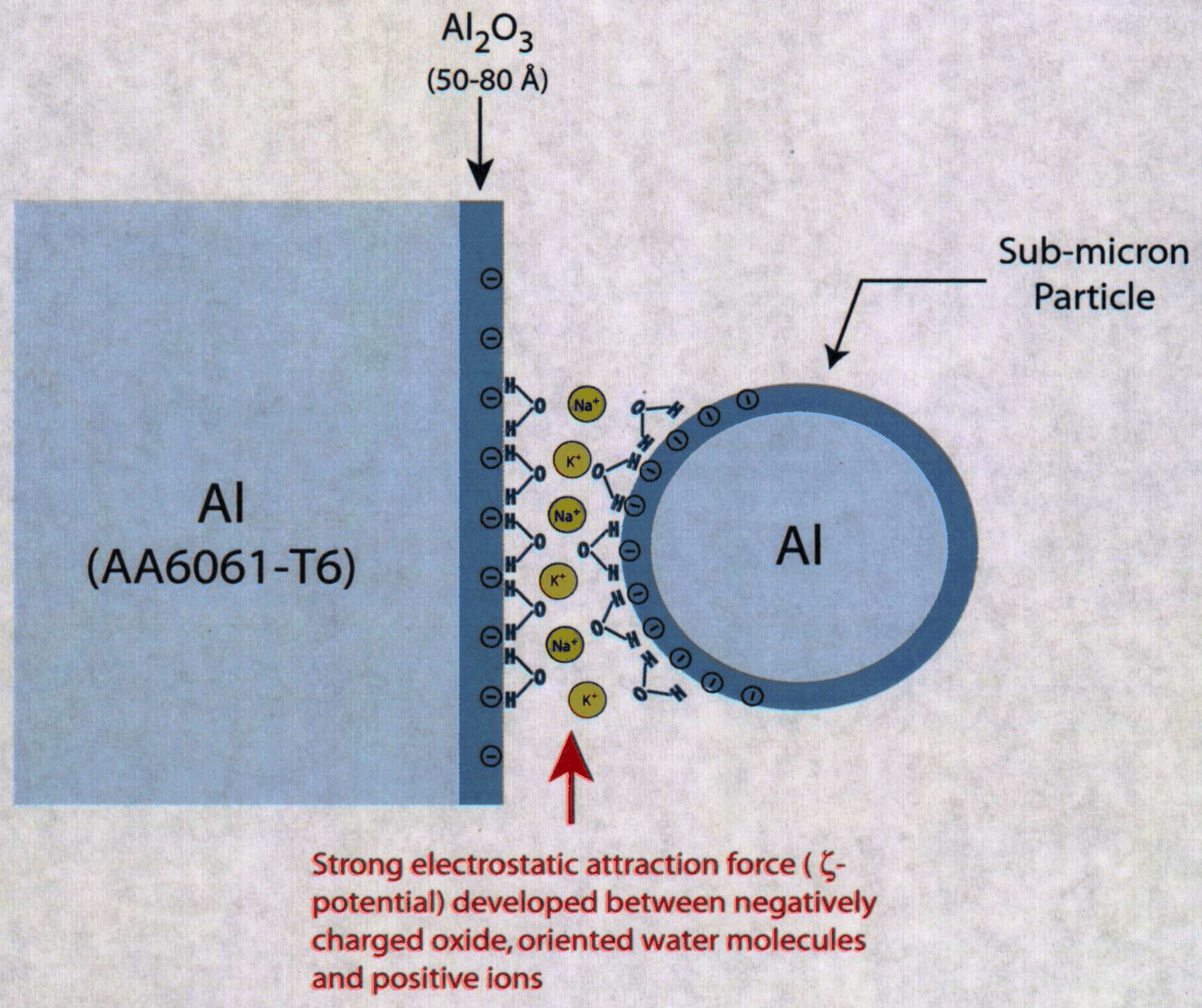

Figure 7 A proposed mechanism to explain how the sub-micron particles adhere to the aluminum surfaces. 
Before Phosphoric Acid Etch

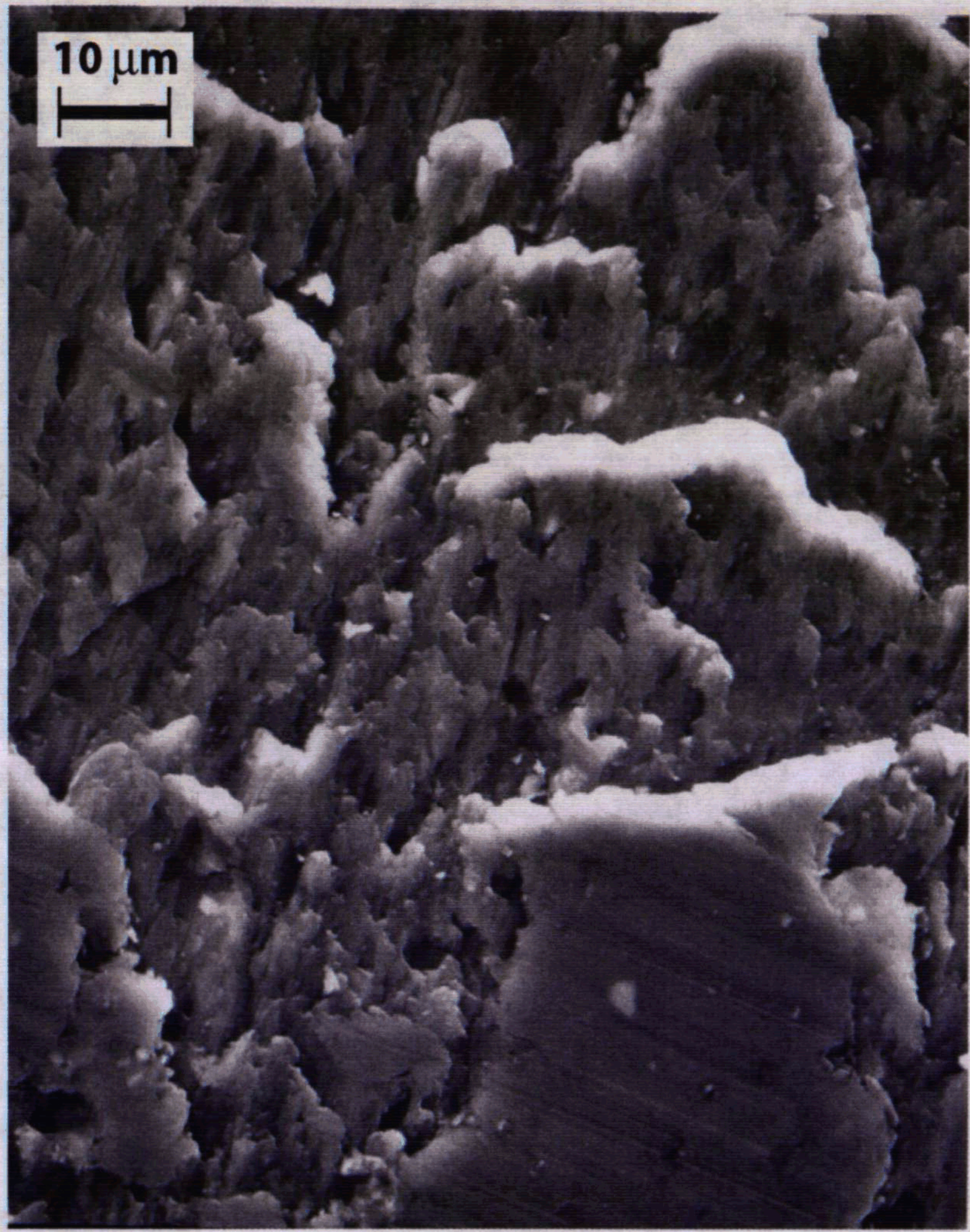

After Phosphoric Acid Etch

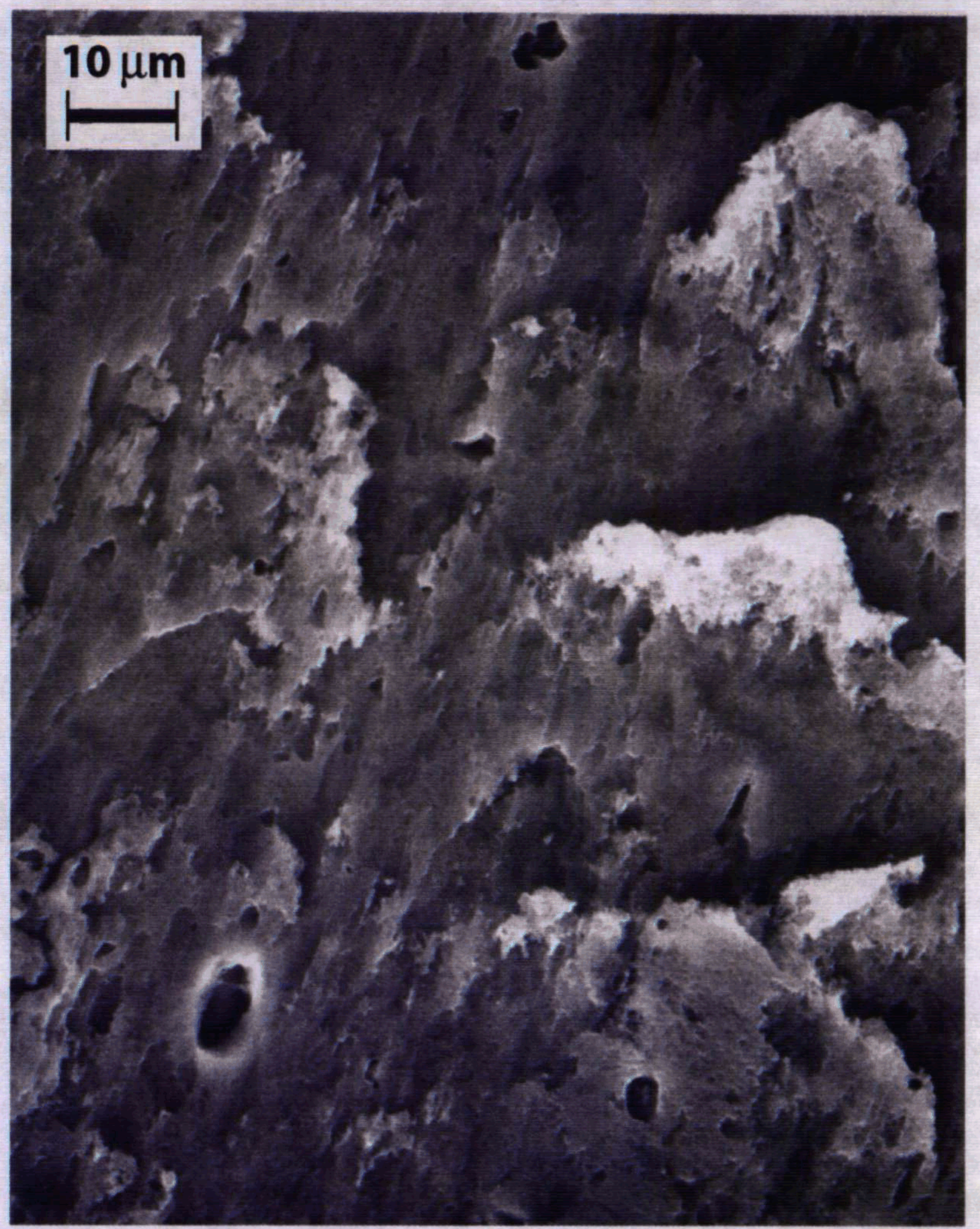

Figure 8 The phosphoric acid dissolved the sub-micron aluminum particles and etched slightly the aluminum surfaces. 
al01.spe: M. Balooch: unknown surface contamination

1974 Feb 4 Al mono $102.0 \mathrm{~W} 100.0 \mu 45.0^{\circ} 117.40 \mathrm{eV}$

$5.5090 \mathrm{e}+004 \max$

Su1s/Area1: Al surface HP/1 (SG7)

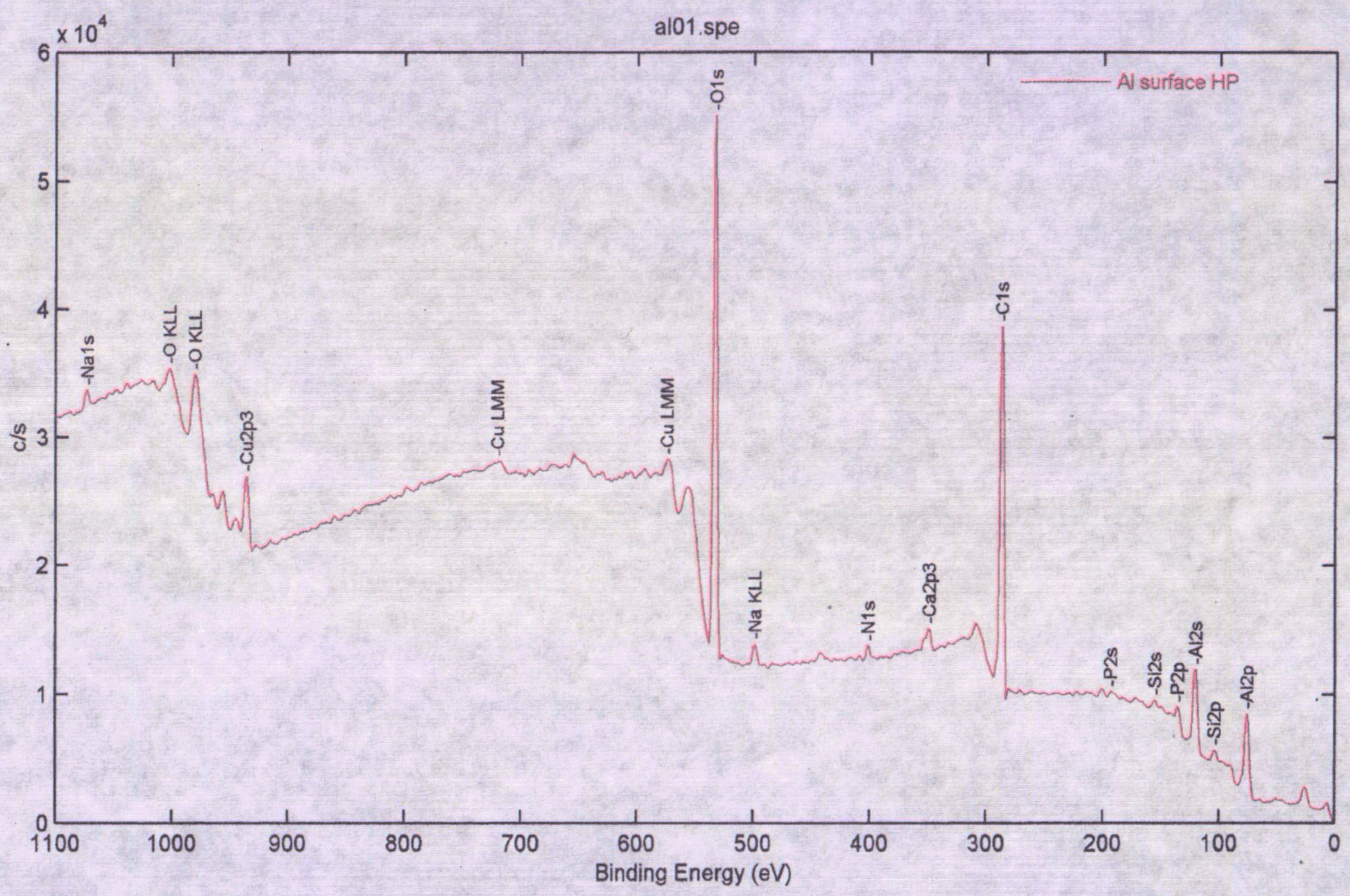

Figure 9 The XPS result on a aluminum sample etched with $30 \%$ phosphoric acid. Small P peak was detected at $133.8 \mathrm{eV}$. 


\section{Appendix I}

\section{OAB Cleaning Process Procedure for Aluminum}

\section{Gross Cleaning Process (Aluminum) Formula G1}

$12 / 7 / 2000$

Parameters:

\section{Process:}

Pressure
Surfactant
Rinse
Angle
Direction
Temperature

\section{PSI}

3-5\% Brulin 1990GD

10-18 Mega-ohm DI Water

$\sim 45$ degrees

Top to bottom \& side to side

$130-150^{\circ} \mathrm{F}$

1. High Pressure spray one side of the part with Brulin at $8-10^{\prime \prime}$ away from the surface at a rate of aproximately $6 \mathrm{~m} / \mathrm{sec}$. Spray top to bottom and side to side.

2. Use a coarse brush to scrub the surface one time with a circular motion and side to side on the edges.

3. Repeat the Brulin spray as in step 1 .

4. Use a medium brush to scrub the surface one time with a circular motion and side to side on the edges.

5. Flip the part to clean the other side.

6. Repeat steps 1 - 4 on the second side.

7. High Pressure spray both sides of the part with Brulin at 1-3" away from the surface at a rate of $3-4 " / \mathrm{sec}$.

8. High Pressure DI Spray 1-3" from the part at a rate of 3-4"/sec. Spray top to bottom and side to side.

9. Transport to Class 1000 Precsion Mechanical cleaning Room

10. Precision clean parts utilizing the Small Mechanical Parts Gross and Precision Cleaner

\section{Precision Cleaning Process: Automated Ultrasonic Cleaner (for Small Parts)}

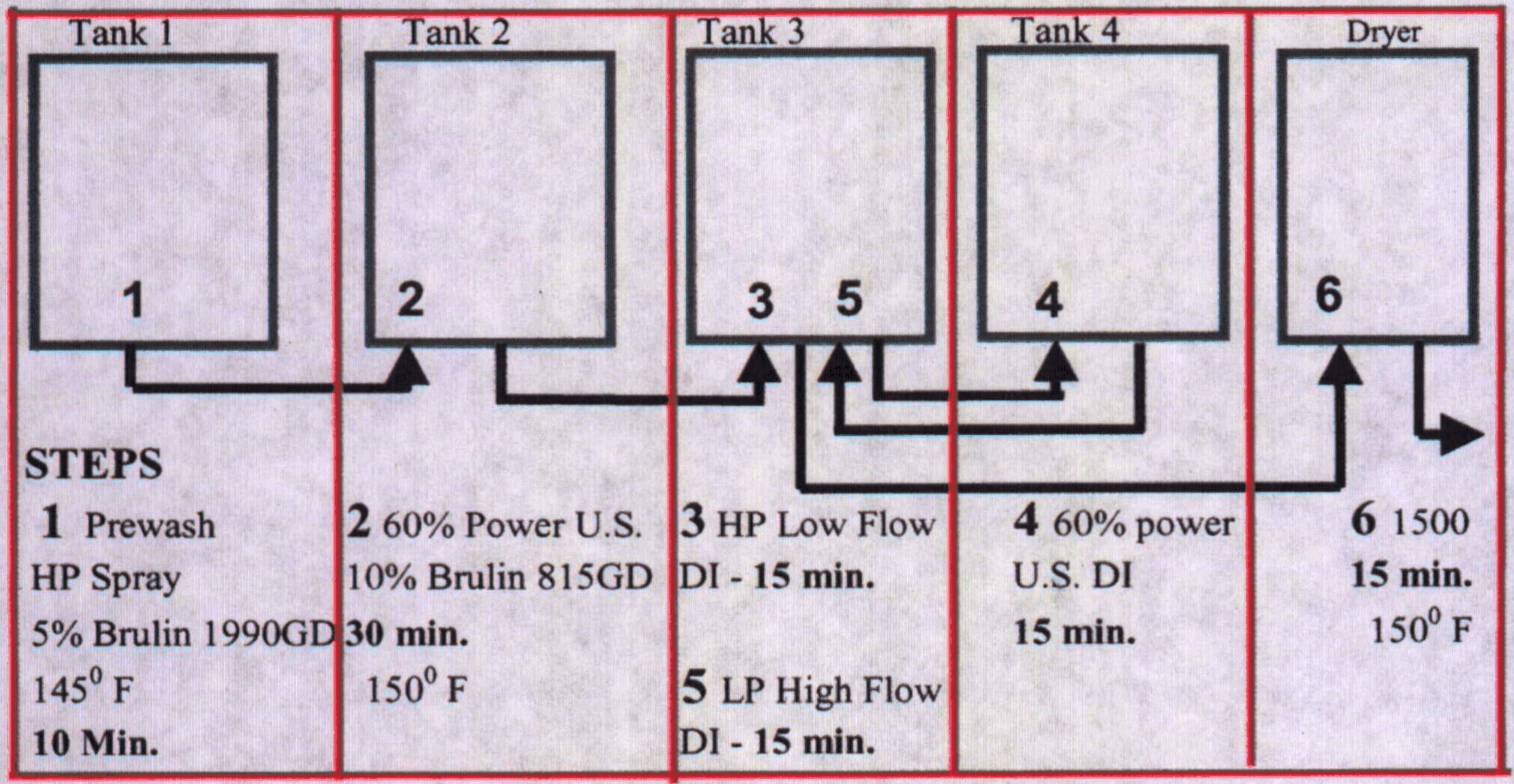




\section{OAB Large Mechanical Parts Precision Cleaner}

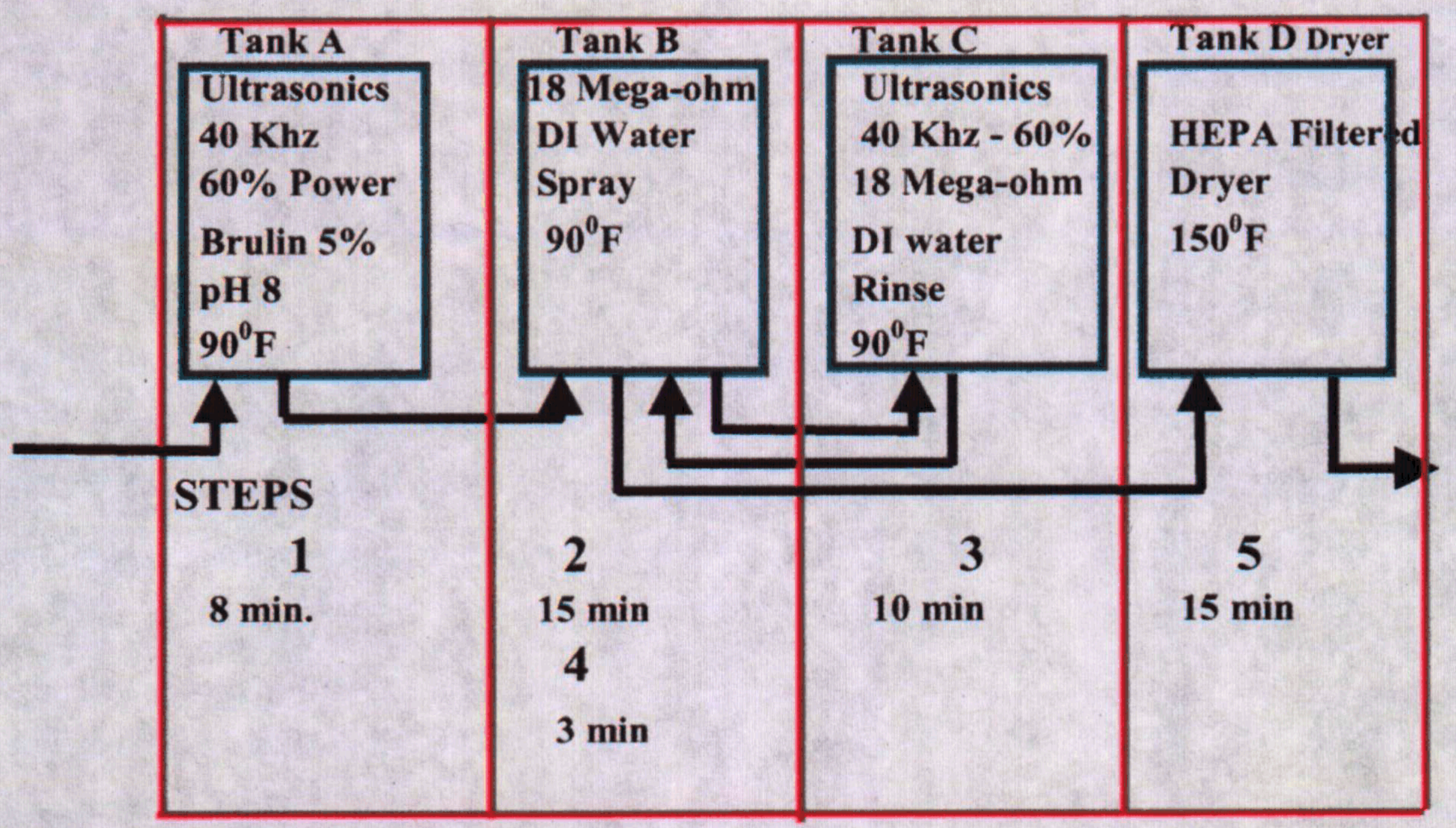

Version 1 


\section{Appendix II}

\section{Results of EDS analysis on the particles in swipe paper}

st: strong peak; m: medium; t: trace

\section{Before Cleaning}

\begin{tabular}{c||c|c|c|c|c|c|c|c|c|c|c|c|c|c|c} 
& Size $(\mu \mathrm{m})$ & $\mathrm{O}$ & $\mathrm{N}$ & $\mathrm{Mg}$ & $\mathrm{Al}$ & $\mathrm{Si}$ & $\mathrm{S}$ & $\mathrm{Cl}$ & $\mathrm{Ca}$ & $\mathrm{Ti}$ & $\mathrm{Cr}$ & $\mathrm{Fe}$ & $\mathrm{Ni}$ & $\mathrm{Cu}$ & Type of Particle \\
\hline $\mathrm{P} 9$ & $15 \times 15$ & & & & & & & & & & & st & & & Iron \\
\hline $\mathrm{P} 12$ & $10 \times 5$ & & & & st & & & & & & & & & & Al particle \\
\hline $\mathrm{P} 1$ & $10 \times 10$ & $\mathrm{~m}$ & & & st & $\mathrm{m}$ & & & $\mathrm{m}$ & & & $\mathrm{t}$ & & & Al + lubricant \\
\hline $\mathrm{P} 7$ & $10 \times 10$ & & & & st & & & & & & & & & & Al particle \\
\hline $\mathrm{P} 2$ & $5 \times 5$ & st & $\mathrm{m}$ & & st & $\mathrm{t}$ & & $\mathrm{m}$ & $\mathrm{m}$ & & & & & & Al + lubricant \\
\hline $\mathrm{P} 10$ & $5 \times 5$ & st & & $\mathrm{m}$ & $\mathrm{m}$ & $\mathrm{st}$ & $\mathrm{t}$ & & $\mathrm{st}$ & & & & & & Al + lubricant \\
\hline $\mathrm{P} 8$ & $5 \times 3$ & $\mathrm{~m}$ & & & st & & $\mathrm{m}$ & & $\mathrm{m}$ & & & & & & Al + lubricant \\
\hline $\mathrm{P} 3$ & $3 \times 1$ & $\mathrm{t}$ & & & st & & & & & & & & & & Al particle \\
\hline $\mathrm{P} 6$ & $2 \times 2$ & & & & st & & & & & & & & & & Al particle \\
\hline $\mathrm{P} 4$ & $2 \times 0.5$ & & & & st & & & & & & & & & & Al particle \\
\hline P11 & $2 \times 0.5$ & & & & st & & & & & & & & & & Al particle \\
\hline P5 & $1.5 \times 0.2$ & & & & st & & & & & & & & & & Al particle
\end{tabular}

\begin{tabular}{|c|c|c|c|c|c|c|c|c|c|c|c|c|c|c|c|}
\hline \multicolumn{16}{|c|}{ After Gross Cleaning } \\
\hline & Size $(\mu \mathrm{m})$ & 0 & $\mathrm{~N}$ & $\mathrm{Mg}$ & Al & $\mathrm{Si}$ & $\mathrm{S}$ & $\mathrm{Cl}$ & $\mathrm{Ca}$ & $\mathrm{Ti}$ & $\mathrm{Cr}$ & $\mathrm{Fe}$ & $\mathrm{Ni}$ & $\mathrm{Cu}$ & Type of Particle \\
\hline P11 & $4 \times 0.5$ & & & & $t$ & $\frac{t}{t}$ & & & & & st & st & $\mathrm{m}$ & & stainless steel \\
\hline $\mathrm{P} 6$ & $2 \times 2$ & 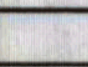 & & & st & 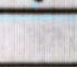 & & & & - & & & & & Al particle \\
\hline P7 & $2 \times 2$ & 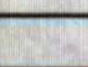 & & & $\mathrm{m}$ & & 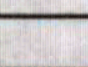 & 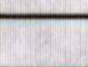 & & 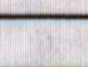 & 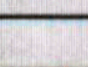 & st & 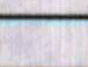 & & \\
\hline $\mathrm{P} 12$ & $2 \times 2$ & & & & st & - & & & & & - & & 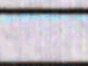 & & Al particle \\
\hline P5 & $2 \times 0.5$ & & & & st & & & & & & & & & & Al particle \\
\hline $\mathrm{PB}$ & $2 \times 0.5$ & & $t$ & & $t$ & $t$ & & 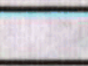 & & & st & st & $\mathrm{m}$ & & stainless steel \\
\hline $\mathrm{P} 1$ & $1.5 \times 1$ & $t$ & & & st & & & & & & & & & & Al particle \\
\hline P19 & $1.5 \times 1$ & & & & st & & & & & & & & 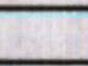 & & Al particle \\
\hline P3 & $1 \times 1$ & $t$ & & & $m$ & & & & & & & st & & & Iron oxide \\
\hline $\mathrm{P} 10$ & $1 \times 1$ & $t$ & & & $m$ & & & 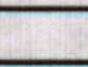 & & & & st & & & Iron oxide \\
\hline $\mathrm{P} 13$ & $1 \times 1$ & & 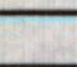 & - & st & & & 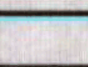 & & & & & & & Al particle \\
\hline P14 & $1 \times 1$ & 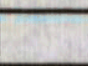 & & & $t$ & & 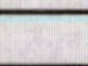 & . & & 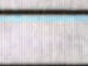 & & st & 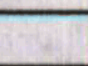 & & Iron oxide \\
\hline P15 & $1 \times 1$ & & & & st & & & & & & & & & & Al particle \\
\hline P17 & $1 \times 1$ & e & & & st & & & & & & 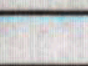 & - & 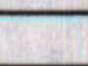 & & Al particle \\
\hline P9 & $1 \times 0.5$ & - & & & st & & 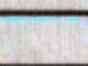 & 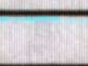 & & & - & & & & Al particle \\
\hline P16 & $1 \times 0.5$ & 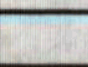 & & & st & & 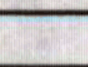 & - & & & 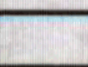 & & - & & Al particle \\
\hline P18 & $1 \times 0.5$ & & 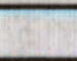 & & & & & & & & - & st & & & Iron oxide \\
\hline P2 & $0.5 \times 0.5$ & & & & st & & - & 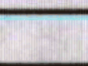 & & 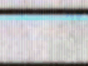 & 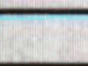 & & & & Al particle \\
\hline $\mathrm{P} 20$ & $0.5 \times 0.5$ & & & & st & & & & & & - & & & & Al particle \\
\hline P4 & $0.5 \times 0.3$ & $\bar{t}$ & & & st & & & & & & & & & & Al particle \\
\hline
\end{tabular}

After Precision Cleaning

\begin{tabular}{|c|c|c|c|c|c|c|c|c|c|c|c|c|c|c|c|}
\hline & Size $(\mu \mathrm{m})$ & 0 & $\mathrm{~N}$ & $\mathrm{Mg}$ & $\mathbf{A}$ & $\mathrm{Si}$ & $\mathrm{S}$ & $\mathrm{Cl}$ & $\mathrm{Ca}$ & $\mathrm{Ti}$ & $\mathrm{Cr}$ & $\mathrm{Fe}$ & $\mathrm{Ni}$ & $\mathrm{Cu}$ & Type of Particle \\
\hline $\mathrm{P} 1$ & $10 \times 1$ & & & & st & & & & & & & & & & Al particle \\
\hline P15 & $7 \times 3$ & & & & st & & & & & & & & & & Al particle \\
\hline P11 & $3 \times 1$ & & & & st & & & & & & & & L & & Al particle \\
\hline P8 & $2 \times 3$ & & & & st & $t$ & & & & & & $\bar{t}$ & & & $\alpha$-eutectic \\
\hline $\mathrm{P7}$ & $2 \times 1$ & & & & st & & & & & & & & & & Al particle \\
\hline P13 & $2 \times 0.5$ & & & & st & & & & & & & & & & Al particle \\
\hline $\mathrm{P} 20$ & $2 \times 0.5$ & & & & st & & & & & & & & & & Al particle \\
\hline P17 & $1 \times .5$ & & & & st & & & & & & & & & & Al particle \\
\hline $\mathrm{P} 4$ & $1 \times 1$ & & & & st & & & & & & & & & & Al particle \\
\hline P5 & $1 \times 1$ & & & & & Z & & & & & st & st & st & & stainless steel \\
\hline $\mathrm{P} 6$ & $1 \times 1$ & & & & st & & & & & & & & & & Al particle \\
\hline P9 & $1 \times 1$ & & & & st & $t$ & & & & & & $t$ & & & $\alpha$-eutectic \\
\hline P10 & $1 \times 1$ & & & E & st & & & & & & & & & & Al particle \\
\hline P12 & $\overline{1 \times 1}$ & & & $\bar{t}$ & st & $t$ & & & & & & & & & Al particle \\
\hline P16 & $1 \times 1$ & st & & & & & & & & & & st & & & Iron oxide \\
\hline
\end{tabular}




\begin{tabular}{c||c|c|c|c|c|c|c|c|c|c|c|c|c|c|c}
\hline P19 & $1 \times 1$ & & & & st & & & & & & & & & & Al particle \\
\hline P2 & $0.5 \times 0.5$ & & & & & & & & & & & st & & & Iron oxide \\
\hline P3 & $0.5 \times 0.5$ & & & & & & & & & & st & st & st & & stainless steel \\
\hline P18 & $0.5 \times 0.5$ & st & & & $\mathrm{t}$ & & & & & & & st & & & Iron oxide \\
\hline P14 & $0.5 \times 0.5$ & & & & st & $\mathrm{t}$ & & & & & & $\mathrm{t}$ & & & $\alpha$-eutectic
\end{tabular}

24 Hours After Precision Cleaning

\begin{tabular}{|c|c|c|c|c|c|c|c|c|c|c|c|c|c|c|c|}
\hline & Size $(\mu \mathrm{m})$ & $\mathrm{O}$ & $\mathrm{N}$ & $\mathrm{Mg}$ & Al & $\mathrm{Si}$ & $\mathrm{S}$ & $\mathrm{Cl}$ & $\mathrm{Ca}$ & $\mathrm{Ti}$ & $\mathrm{Cr}$ & $\mathrm{Fe}$ & $\mathrm{Ni}$ & $\mathrm{Cu}$ & Type of Particle \\
\hline P8 & $5 \times 2$ & & - & $t$ & st & $t$ & & & & & & & & & Al particle \\
\hline $\mathrm{P} 2$ & $4 \times 2$ & - & - & & st & $t$ & & 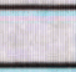 & & & & $t$ & & & $\alpha$-eutectic \\
\hline P5 & $4 \times 2$ & $\mathrm{~m}$ & & $t$ & st & $t$ & & & & & & + & & & Al particle \\
\hline P16 & $3 \times 2$ & & - & & st & $t$ & & & & & & & & & Al particle \\
\hline P3 & $3 \times 1$ & $\mathrm{~m}$ & & & st & $t$ & & & & & & $t$ & & & $\alpha$-eutectic \\
\hline P15 & $3 \times 1$ & 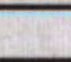 & & & st & $t$ & & & & & & & & & Al particle \\
\hline P11 & $3 \times 0.5$ & & & $t$ & st & $t$ & & & & & & - & & & Al particle \\
\hline $\mathrm{P} 6$ & $2 \times 2$ & $\mathrm{~m}$ & & - & $\mathrm{m}$ & $t$ & & $m$ & $\mathrm{~m}$ & & $t$ & $m$ & & & stainless steel \\
\hline $\mathrm{P} 20$ & $2 \times 1$ & & & & st & - & & 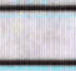 & & & & 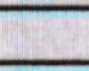 & & & Al particle \\
\hline $\mathrm{P} 4$ & $2 \times 0.5$ & $\mathrm{~m}$ & & $t$ & st & $t$ & & & & & & & & & Al particle \\
\hline P7 & $2 \times 0.5$ & $t$ & & & st & $t$ & & & & & & $t$ & & & Al particle \\
\hline P13 & $10 \times 3$ & st & & & $t$ & & & & & st & & & & & $\mathrm{TO}_{2}$ \\
\hline $\mathrm{P1}$ & $10 \times 10$ & $\mathrm{~m}$ & st & & $m$ & & $m$ & $m$ & & & st & & & & detergent \\
\hline P9 & $1.5 \times 1.5$ & $\mathrm{~m}$ & & & $m$ & & & & & & & & & & Alumina \\
\hline $\mathrm{P} 14$ & $1.5 \times 1.5$ & & & & $t$ & & & & & & st & st & $t$ & $t$ & stainless steel \\
\hline P10 & $1 \times 1$ & st & & & $t$ & & & & & & st & st & & & stainless steel \\
\hline P17 & $1 \times 0.5$ & & & & st & $t$ & & & & & & & & & Al particle \\
\hline P18 & $1 \times 0.5$ & & & & st & $\bar{t}$ & & & & & & & & & Al particle \\
\hline P19 & $1 \times 0.5$ & & & & st & $t$ & & & & & & $\bar{t}$ & & & Al particle \\
\hline P12 & $0.5 \times 0.5$ & $m$ & & & st & & & & & & & & & & Al particle \\
\hline
\end{tabular}

